\title{
Süleyman Demirel Üniversitesi Tıp Fakültesi Hastanesinde Organ Nakli Merkezi Kurulması
}

\author{
Establishment of Suleyman Demirel University Medical Faculty Hospital Organ \\ Transplant Center
}

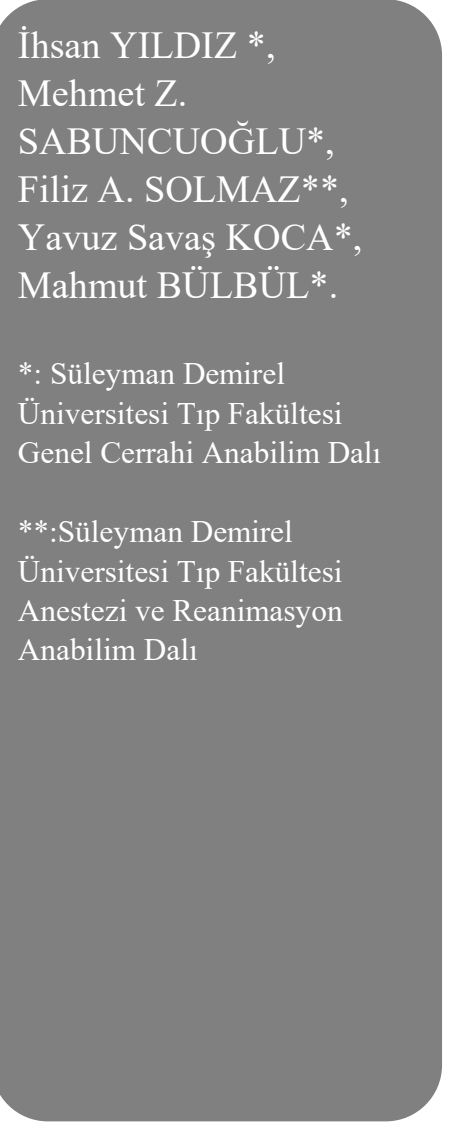

Yazışma Adresi:

Dr.Öğr. Üyesi İhsan Yıldız

Süleyman Demirel Üniversitesi Tip

Fakültesi Genel Cerrahi Anabilim

Dalı

32260 - ISPARTA

05065615647

drihsanyildiz@gmail.com

\section{$\ddot{\mathbf{O z}}$}

Giriş ve Amaç:

Organ nakli, multidisipliner yaklaşımla yapılan, büyük emek, özveri ve fedakarlık gerektiren bir ekip çalışmasıdır.

Her yıl nakil merkezi sayısı artmakta ancak organ nakli sayısal olarak ihtiyacı karşılamamakta ve açık giderek büyümektedir. Bu açığın kapatılabilmesi için bölgede özellikle üniversite hastanelerinde organ nakli merkezi kurulmasının gereklidir.

Çalışmanın amacı, 15.05.2015 tarihinde Süleyman Demirel Üniversitesi (SDÜ) Tıp Fakültesi Organ Nakli Merkezi kurulması ve deneyimlerimzi paylaşmaktı.Materyal ve Metod:Öncelikle SDÜ Tıp Fakültesi hastanesinde görev yapan akademik personelin eğitimi ve sertifikalı organ nakli koordinatörü çalışmada yer aldı.

Tıp Fakültesi Hastanesi ameliyathaneleri, mekanik ventilatör destekli yoğun bakım üniteleri, eczane, laboratuarlar, organ nakli polikliniği, hemodiyaliz ünitesi ve yataklı servis gibi teknik alt yapı hazırland. Eğitimli sağlık çalışanları, teknik ve yardımcı personel organ nakli için hazır hale getirildi. Isparta ve çevresinde hizmet veren 112 acil, hastaneler, hemodiyaliz üniteleriyle bilgilendirme-tanitım ve koordinasyon toplantıları yapıldı. Tartışma: Bir üniversite hastanesinde organ nakli merkezi kurulumu sabır, özveri, emek ile birlikte birçok birimle koordineli çalışmayı gerektiren multidisipliner bir yaklaşımla sağlanabilir. Neredeyse tüm branşları ilgilendiren nakil programı bu anlayıș içinde yürütülmektedir. Sonuç:Ôncelikle deneyimli bir akademik kadro ile birlikte tıbbi ve teknik alt yapının hazırlanması organ nakli merkezinin kurulamasında temel önceliklerdir. Bu sıralamayla uyularak bir üniversite hastanesinde organ nakli merkezi kurmak mümkündür.

Anahtar kelimeler: organ nakli, böbrek nakli, karaciğer nakli.

\section{Abstract:}

Background:Organ transplantation is a teamwork that requires a multidisciplinary approach, big effort, dedication and sacrifice. 
Despite an increasing number of transplant centers each year, they can not meet the organ requirements and organ deficit is increasing in our country. In order to eliminate this deficit,we consider that a transplant center should be established at a university hospital in the region.

The aimof the study is to share our experiences with the Organ Transplant Center of Süleyman Demirel University, which was established on 15/05/2015.Materials and Methods:First, the training of academic staff of Süleyman Demirel University Medical Faculty hospital and transplant coordinators took part in the study.

Süleyman Demirel University Hospital's operating rooms, intensive care units, pharmacies, laboratories, transplant outpatient and hemodialysis unit, inpatient services and technical infrastructure were prepared. Trained health workers, technical and auxiliary staff was made ready for organs transplant. Several informational and coordination meetings were held with 112 emergency, hospitals and dialysis units in this region.Discussion:The establishment of organ transplant center in a university hospital requires, patience, dedication, effort, coordinated working with many units and provided by a multidisciplinary approach. The organ transplantation program involving almost all branches is carried out in this understanding. Conclusion :An experienced academic staff, medical and technical infrastructure, are the main priorities to establish a transplant center.It is possible to establish the transplant center at a university hospital following these rules.

Keywords: organ transplantation, kidney transplantation, liver transplantation.

\section{Giriş ve Amaç:}

Organ nakli, multidisipliner yaklaşımla yapılan, büyük emek, özveri ve fedakarlık gerektiren bir ekip çalışmasıdır. Son zamanlarda dünyada ol- duğu gibi ülkemizde de organ naklinde önemli aşamalar kaydedilmiş olup dünya ile yarışır hale gelmiştir. T.C. Sağlık Bakanlığının öncülügünde ülkemizde organ nakli ve organ paylaşı$\mathrm{m} 1$ konusunda gerek tıbbi yönden gerekse sosyal yönden önemli gelişmeler hayata geçirilmiştir [1,2].

Bakanlığa bağlı olarak organ nakli yapan 96 merkez vardır. Bu merkezlerde 2015 y1lı itibariyle 82 kalp, 26 akciğer, 2870 böbrek, 1087 karaciğer, 7 pankreas nakli yapılmıştır. Bakanlik organ bekleme listesinde ise $631 \mathrm{kalp}, 50$ akciğer, 22258 böbrek, 2241 karaciğer, 266 pankreas nakli bekleyen hasta vardır [2]. Ülkemiz organ nakli sayısal olarak ihtiyacı karşılamamaktadır. Her yıl nakil merkezi sayısı artmakta ancak buna paralel hasta sayısı da artmaktadır. Bu açığın kapatılabilmesi için bölgede özellikle üniversite hastanelerinde organ nakli merkezi kurulması gerekli olmaktadır.

Ülkemizde 01.06.2000 tarih ve 24066 say1l Resmi Gazetede yayımlanarak yürürlüğe giren Organ ve doku nakli hizmetleri 2238 say1l "Organ ve Doku Alınması, Saklanması ve Nakli Hakkında Kanun" ile "Organ ve Doku Nakli Hizmetleri Yönetmeliği”" kapsamında yürütülmektedir. T.C. Sağlık Bakanlığı 26.02.2001 tarih ve 1832 sayılı onayı ile yürürlüğe giren “Organ Nakli Merkezleri Yönergesi'ne uygun olarak üniversitemizde 15.05.2015 tarihinde Organ Nakli Merkezi kurulmuştur.

Çalışmanın amacı, Süleyman Demirel Üniversitesi (SDÜ) Tıp Fakültesi Organ Nakli Merkezi kurulması ve bu konudaki yaşanan deneyimlerimzi paylaşmaktı.

\section{Materyal ve Metod:}

Öncelikle SDÜ Tıp Fakültesi hastanesinde görev yapan akademik personelin eğitimi ile ilk adım atıldı. Bu doğrultuda daha önceden karaciğer, böbrek nakli cerrahisinde eğitimli iki akademisyen ve birinci aşamada bu akademisyenlere destek olacak iki akademisyen de görevlendirildi. Anestezi departmanında görevli 
iki akademisyen de ekipte yer aldı. Yine organ nakli konusunda eğitimli iki akademisyen nefrolog ekipte yer aldı. Daha önceden organ nakli konusunda eğitimli ve sertifikalı üç organ nakli koordinatörü çalışmada yer aldı.

T1p Fakültesi Hastanesi ameliyathaneleri, mekanik ventilatör destekli yoğun bakım üniteleri, eczane, laboratuarlar, organ nakli polikliniği, hemodiyaliz ünitesi ve yataklı servis gibi teknik alt yapı hazırlandı. Eğitimli sağlık çalışanları, teknik ve yardımcı personel organ nakli için hazır hale getirildi. Isparta ve çevresinde hizmet veren 112 acil, hastaneler, hemodiyaliz üniteleriyle bilgilendirme -tanıtım ve koordinasyon toplantıları yapıldı.

T.C. Sağlık bakanlığına organ nakli için müracaat edilip 15.05.2015 tarihinde ruhsat ve faaliyet izni alındi.

\section{Tartışma:}

Bir üniversite hastanesinde organ nakli merkezi kurulumu sabır, özveri, emek ile birlikte birçok birimle koordineli çalışmayı gerektiren multidisipliner bir yaklaşımla sağlanabilir. Neredeyse tüm branşları ilgilendiren nakil programı bu anlayış içinde yürütülmektedir [1,3-5].

Bizim çalışmamız da bu doğrultuda planlanarak hayata geçirildi. Öncelikle eğitimli akademisyen ihtiyacı karşılandi. Bu gereklilikle karaciğer nakli için bir akademisyen yılda yaklaşık 250-300 karaciğer naklinin yapıldığı bir merkezde bir y1l süreyle eğitim ve sertifikasyon programına katıldı. Daha önceden, yılda ortalama 500 böbrek naklinin yapıldığı bir merkezde iki yıl çalışmış bir akademisyen de programa katıldı. Yeni açılan bir merkezlerde kısa zamanda nakil programının başlatılmasında en az cerrahi ekibin deneyimi kadar nefrologların da deneyimi gereklidir. $\mathrm{Bu}$ doğrultuda bir akademisyen de yurt dişında bir merkezde organ nakli konusunda eğitim almıştı.

Bütün bunların yanında hastane içinde gerek akademik kadrolar gerekse tıbbi personel ile ciddi işbirliği sağlanması gerekmektedir [3]. Bu konuda hem anabilim dalı başkanı hem de diğer öğretim üyeleriyle koordinasyon içinde bulunularak onların desteği sağlandı.

Organ naklinin teknik desteklerini sağlayan hastane içi koordinatörlerin özverili çalışmaları da konuya büyük destek sağlamaktadır. Bu konuda hastane içinde sertifikalı iki nakil koordinatörü bize tam destek sağladı. Bölgede bir üniversite hastanesi olarak kısa zamanda ruhsat ve faaliyet izni alıp nakil programına başlamak temel amaçtı.

Gelinen son noktada T.C. Sağlık Bakanlığından faaliyet izni alınıp organ nakli merkez kurulmas1 işlemi tamamland.

Yapılan bu çalışmada amaç, organ nakli merkezini kurarak bölgede yaşayan hastalara yakından hizmet vermek ve tedavilerini yakından izlemekti. Bu konuda kısa zamanda kismı bir başarı sağlansa da henüz yeterli bir düzeye gelinememiştir. Bağışlanan organların aynı bölgedeki hastalara nakledilmesi temel olarak amaçlanmış ve sonuçta üç ay içinde üç böbrek ve bir karaciğer nakli başarıyla yapılmıştır.

\section{Sonuç:}

Öncelikle deneyimli bir akademik kadro daha sonra da tıbbi ve teknik alt yapının hazırlanmas1 organ nakli merkezinin kurulamasinda temel önceliklerdir. $\mathrm{Bu}$ temel ilkelere uyularak bir üniversite hastanesinde organ nakli yapmak mümkündür.

\section{Kaynaklar:}

1. Kalayoğlu M. Starting a liver transplant program in Turkey; Akdeniz University model. Turk J Gastroenterol. 2008 Mar;19(1):1

2. web https://organ.saglik.gov.tr

3.Silva VS, Moura LC, Leite RF, Oliveira PC, Schirmer J, Intra-hospital organ and tissue donation coordination project: cost-effectiveness and social benefits. Roza Rev Saude Publica. 2015;49:1-7

4. Yakupoğlu YK, Özden E, Koçak B. Three Years 
of Kidney Transplantation Experience at a University Hospital. Turkish Nephrology, Dialysis and Transplantation Journal 2009 Vol. 18, No, 2, 76-81

5. Tuncer M, Gürkan A, Yücetin L, Ersoy F, Demirbaş A, Akaydin M, Yakupoglu G. Evaluation of transplantation in one center: Akdeniz University model. Transplant Proc. 2002 Sep;34(6):2012-3. 